\title{
Rotor Resistance Estimator based on Virtual Current Sensor Algorithm for Induction Motor Drives
}

Michał Adamczyk

Department of Electrical Machines, Wroclaw University of Science and Technology, Drives and Measurements, Wybrzeze Wyspianskiego 27, 50-370, Wrocław, Poland

Received July 23, 2020; Accepted September 02, 2020

Abstract: In this article, model reference adaptive system (MRAS)-based estimator of a rotor resistance of an induction motor (IM) is presented. In contrast to the solutions known from the literature, the reference model of this estimator uses the measured values of the phase current and the adaptive part is a virtual current sensor. The article presents an accurate description of the algorithm taking into account the discrete equations for possible practical implementation in the microprocessor system. In the first step, the impact of motor parameters to stator current estimation quality in the adaptive model was checked. Subsequently, simulation tests of the proposed rotor resistance estimator were carried out for the field-oriented control of the induction motor drive system with a model of an induction motor with fixed parameters and an induction motor with a changing main inductance according to a magnetisation curve. The analysis of the estimator's work showed its high efficiency and insensitivity to changes in the IM main inductance.

Keywords: induction motor drive $\bullet$ rotor resistance estimator $\bullet$ model reference adaptive system $\bullet$ virtual current sensor $\bullet$ fault tolerant control

\section{Nomenclature}

$\Psi_{s}, \Psi_{r}, \Psi_{m}$ - spatial vectors of the stator, rotor and magnetic fluxes,

$\mathbf{i}_{s}, \mathbf{i}_{r}, \mathbf{i}_{m} \quad$ - spatial vectors of the stator, rotor and magnetic currents,

$\mathbf{u}_{s} \quad-$ spatial vector of the stator voltage,

$t_{\mathrm{e} m}, t_{L} \quad-$ electromagnetic and load torques,

$\omega_{m} \quad-$ angular speed,

$I_{m}, l_{\sigma s}, l_{\sigma r} \quad$ - main, stator and rotor winding leakage inductances,

$r_{s}, r_{r} \quad-$ the stator and rotor winding resistances.

All state variables and parameters are expressed in per unit system [p.u.].

\section{Introduction}

In induction motor (IM) drives, precise control techniques belong to the group of vector methods (Orlowska-Kowalska and Dybkowski, 2016). The most popular ones are the direct torque control (DTC) and the direct rotor flux oriented control (DRFOC). There are difficulties in measuring state variables such as vectors of rotor flux $\Psi_{r}$ and stator flux $\Psi_{s}$. These variables should be estimated (Dybkowski, 2018) based on measured signals. 
All model-based estimators of state variables use parameters of the IM. An accurate identification is very important to correct the operation of the IM drive system. However, the parameters are susceptible to change their values in time, according to a work point and temperature of the windings. Therefore, for increasing the efficiency of the IM drive systems, the use of estimators of the IM parameters is highly recommended.

The literature provides a detailed overview of methods for estimating the selected IM parameters (Toliyat et al., 2003). The techniques presented here can be divided into two groups: working online and offline.

Nowadays, many induction motors work with inverters produced by different companies. Therefore, it is usually necessary to determine the IM parameters before the target operation, which is done by offline identification. This way, by using, e.g. the idle-running and short-circuit tests the parameters of the IM equivalent scheme can be determined with a certain degree of accuracy. This solution allows the use of vector control methods, but in this case, it is assumed that the identified parameters are constant over the entire range of operation. Since the parameters change depending on many factors such as the change in the temperature of the windings or the changes in the drive operating point, this is not a precise solution but only sufficient.

To increase precision in IM control, online parameter estimation methods should be used. Such a solution allows us to estimate parameter values during the system operation. This is particularly important for systems that operate under conditions such as field weakening, where the main inductance changes. It should also be remembered that a long operation time has an impact on temperature changes in windings, and consequently, changes in the winding resistance values.

The rotor resistance is one of the IM parameters that significantly affect the accuracy of control and in particular the accuracy of estimation of motor state variables. This parameter can be estimated online based on various techniques, and is divided into four groups: spectral analysis techniques, observer-based techniques, Model Reference Adaptive System (MRAS)-Based Techniques and other methods.

Spectral analysis techniques uses the analysis of characteristic harmonics in measured values of stator currents and/or voltages (Zai et al., 1992; Loron and Laliberte, 1993). Among the observer-based techniques, the extended Kalman filters (EKF) (Barut et al., 2012; Zerdali and Barut, 2018; Horváth and Kuslits, 2018) and extended Luenberger observers (ELO) are popular (Orlowska-Kowalska, 1989; Du and Brdys, 1993). In the case of EKF, a problem with linearisation of the extended mathematical model of IM in each numerical step appears. Also, there are difficulties with the selection of $Q$ and $R$, which are the covariance matrices. ELO is an analytic algorithm and thus its design is much simpler, and the number of calculations required for a given numerical step is disproportionately smaller.

MRAS techniques, based on the reference model and adaptive model are the most popular group. The adaptive model, as opposed to the reference model, utilises the estimated parameter. The aim of the system is the most accurate approximation to its real value so that the adaptive model has the same response as the reference model. MRAS techniques can be used to improve the performance of sate variables estimators and control algorithms. For example, the adaptive structure for the rotor resistance estimator, shown by (Zorgani et al., 2010) was used to improve the performance of the speed estimator MRAS ${ }^{c C}$ (Dybkowski and Orlowska-Kowalska, 2013).

Three methods of estimating the rotor resistance in an adaptive system are presented in Mapelli et al. (2012), based on active power, reactive power and torque, respectively. For all these methods, the sensitivity of the selected rotor resistance estimators to other IM parameters changes, and the correctness of operation at different operating points were tested. The authors have shown that the estimator based on reactive power is insensitive to load torque changes.

In Zorgani et al. (2019), a sensorless drive system with an induction motor operating at very low frequencies is presented. The MRAS type rotor resistance estimator used in this research is based on the relationship between current and voltage stator flux models. The authors demonstrated the stability conditions of the proposed rotor resistance estimator.

Many of the solutions concerning the estimation of the rotor resistance contained in the literature refer to the improvement of IM angular velocity estimation precision. In systems with a higher safety level, it is an alternative to the encoder in case of its damage. It should be mentioned that the current sensors are not reliable either. In the literature, a solution providing vector control of the drive system from the IM in case of loss of the information about measured stator phase currents is known (Adamczyk and Orlowska-Kowalska, 2019). However, also, in this case, precise knowledge of the rotor resistance value is important, because the identified errors worsen the quality of stator current reconstruction.

This article proposes a rotor resistance estimator, based on measured and estimated values of stator currents. This solution also improves the quality of current estimation in case of current sensor failure and is directed to current sensors fault-tolerant control (CS-FTC) systems. 


\section{Mathematical model of an induction motor}

Following the generally accepted simplifications described among others in (Kazmierkowski et al., 2002; OrlowskaKowalska, 2003) IM mathematical model can be presented using differential equations written in a stationary reference frame as follows (in p.u.):

- voltage equation of the stator winding:

$$
\frac{d}{d t} \Psi_{s}=\left(\mathbf{u}_{s}-r_{s} \mathbf{i}_{s}\right) \frac{1}{T_{N}},
$$

- voltage equation of the rotor winding:

$$
\frac{d}{d t} \Psi_{r}=\left(\frac{r_{r}}{l_{r}}\left(l_{m} \mathbf{i}_{s}-\Psi_{r}\right)+j \omega_{m} \Psi_{r}\right) \frac{1}{T_{N}},
$$

- flux-current equations:

$$
\begin{aligned}
& \Psi_{s}=l_{s} \mathbf{i}_{s}+l_{m} \mathbf{i}_{r}, \\
& \Psi_{r}=l_{r} \mathbf{i}_{r}+l_{m} \mathbf{i}_{s},
\end{aligned}
$$

- magnetic flux equation:

$$
\Psi_{m}=\Psi_{s}+l_{\sigma s} \mathbf{i}_{s},
$$

where $I_{s}=I_{\sigma s}+I_{m}, I_{r}=I_{\sigma r}+I_{m}, T_{N}=1 / 2 \pi f_{s N}$ and $f_{s N}-$ nominal frequency.

Equivalent circuit of the induction motor is shown in Figure 1.

The expression for the IM electromagnetic torque is as follows:

$$
t_{e m}=\operatorname{Im}\left(\Psi_{s} \mathbf{i}_{s}^{*}\right),
$$

and the equation of motion is:

$$
\frac{d}{d t} \omega_{m}=\left(t_{e m}-t_{L}\right) \frac{1}{T_{M}}
$$

where $T_{M}$ - mechanical time constant of the drive.

The amplitude of the magnetising current can be represented by the following equation:

$$
\mathrm{i}_{m}=\mathrm{i}_{s}+\mathrm{i}_{r}
$$

In a squirrel-cage IM, it is not possible to measure the rotor current, whereas an assumption (8) in a mathematical model makes the value of the main inductance constant over the whole range of motor operation. Therefore, in the

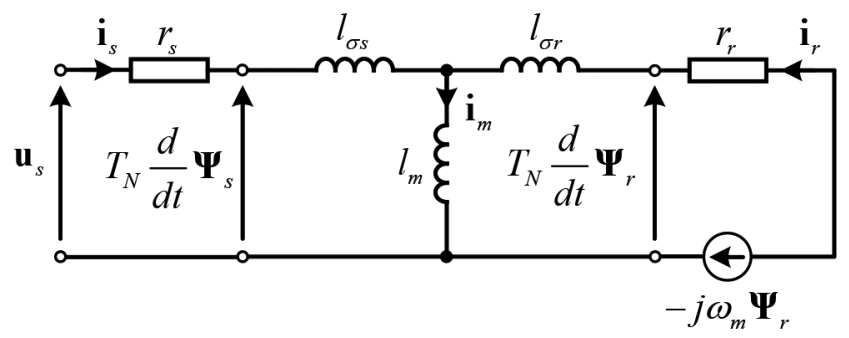

Fig. 1. Equivalent circuit of the induction motor 
mathematical model used in the tests described in this article, an approximate form of the magnetisation curve was adopted, which affects the value of the main inductance $I_{m}$ depending on the motor operating conditions. Under this assumption, the amplitude of the magnetising current depends on the amplitude of the magnetising flux:

$$
\mathrm{i}_{m}=f\left(\Psi_{m}\right)=a \Psi_{m}+(1-a) \Psi_{m}^{b},
$$

where $a=0.7$ and $b=7$ are constants. The method of selecting these coefficients is described in more detail in Levi et al. (2000). Taking into account the above equation, the main inductance $I_{m}$, expressed in p.u., is a parameter depending on the magnetisation flux module $\Psi_{m}$ according to:

$$
l_{m}=\frac{\Psi_{m} / \Psi_{m N}}{\mathrm{i}_{m} / \mathrm{i}_{m N}} l_{m N}=\frac{\Psi_{m N}}{\mathrm{i}_{m N}} l_{m N}\left(a+(1-a) \Psi_{m}^{b-1}\right)^{-1} .
$$

\section{Structure of rotor resistance estimator}

\subsection{Virtual current sensor}

The proposed rotor resistance estimator is based on the virtual current sensor (VCS) presented in Adamczyk and Orlowska-Kowalska (2019). This algorithm is based on equations (1), (2). It may be presented in a discrete form, in a stationary coordinate system $(\alpha-\beta)$ using the following equations:

$$
\begin{aligned}
& i_{s \alpha}^{e}(k+1)=i_{s \alpha}^{e}(k)+\frac{1}{l_{s} \sigma}\left(u_{s \alpha}(k)-r_{s} i_{s \alpha}^{e}(k)-\frac{l_{m}}{l_{r}}\left(\frac{r_{r}}{l_{r}}\left(l_{m} i_{s \alpha}^{e}(k)-\Psi_{r \alpha}^{i}(k)\right)-\omega_{m}(k) \Psi_{r \beta}^{i}(k)\right)\right) \frac{T_{s}}{T_{N}}, \\
& i_{s \beta}^{e}(k+1)=i_{s \beta}^{e}(k)+\frac{1}{l_{s} \sigma}\left(u_{s \beta}(k)-r_{s} i_{s \beta}^{e}(k)-\frac{l_{m}}{l_{r}}\left(\frac{r_{r}}{l_{r}}\left(l_{m} i_{s \beta}^{e}(k)-\Psi_{r \beta}^{i}(k)\right)+\omega_{m}(k) \Psi_{r \alpha}^{i}(k+1)\right)\right) \frac{T_{s}}{T_{N}},
\end{aligned}
$$

whereby the components of the rotor flux vector are estimated based on the current rotor flux model (OrlowskaKowalska, 2003):

$$
\begin{aligned}
& \Psi_{r \alpha}^{i}(k+1)=\Psi_{r \alpha}^{i}(k)+\left[\frac{r_{r}}{l_{r}}\left(l_{m} i_{s \alpha}^{e}(k)-\Psi_{r \alpha}^{i}(k)\right)-\omega_{m}(k) \Psi_{r \beta}^{i}(k)\right] \frac{T_{s}}{T_{N}}, \\
& \Psi_{r \beta}^{i}(k+1)=\Psi_{r \beta}^{i}(k)+\left[\frac{r_{r}}{l_{r}}\left(l_{m} i_{s \beta}^{e}(k)-\Psi_{r \beta}^{i}(k)\right)+\omega_{m}(k) \Psi_{r \alpha}^{i}(k+1)\right] \frac{T_{s}}{T_{N}}
\end{aligned}
$$

This algorithm requires the measurement of the angular speed and the DC bus voltage $u_{d c}$ in the voltage-source inverter (VSI) intermediate circuit. With the assumption that transistors of the VSI are considered as ideal switches, based on the discrete values of $u_{d c}$, the stator voltage vector components are calculated according to:

$$
\begin{aligned}
& u_{s \alpha}(k+1)=\frac{2}{3} u_{d c}(k)\left(S_{A}(k)-\frac{1}{2}\left(S_{B}(k)+S_{C}(k)\right)\right), \\
& u_{s \beta}(k+1)=\frac{\sqrt{3}}{3} u_{d c}(k)\left(S_{B}(k)-S_{C}(k)\right),
\end{aligned}
$$

where $S_{A}, S_{B}, S_{C}$ are logic states of VI connectors and $\sigma=I_{m}{ }^{2} I_{s} I_{r}$ - leakage factor of the motor. The flow chart of the VCS algorithm is shown in Figure 2.

As can be seen above, VCS uses the parameters of the IM equivalent circuit, i.e. rotor resistance $r_{r}$, stator resistance $r_{s}$, main inductance $I_{m}$, the leakage inductance of the rotor $I_{\sigma r}$ and stator $I_{\sigma s}$ windings. In the next subsection, the influence of correct identification of these parameters on the quality of stator current estimation was examined. 


\subsection{Impact of induction motor parameters on the quality of stator current estimation}

The tests of the described VCS were carried out in MATLAB-Simulink environment using method ode 1 with calculation step 6.25e-6, for the IM (mathematical model (1)-(7)) fed from VSI with ideal switches. The quality of stator current estimation was tested for $0.1 \mathrm{~s}$ ( 5 periods of the fundamental frequency) for steady-state, rated speed, and $75 \%$ of rated torque. Figure 3 shows the waveforms of the $i_{s a}$ measured (index $m$ ) and estimated (index $e$ ) stator current component in $\alpha$ axis, for different values of the rotor resistance. The test were carried out for constant nominal values of other IM parameters. The IM parameters are given in Table A1 in the Appendix.

The analysis of Figure 3b,c showed that the rotor resistance has a large impact on the estimation quality of the stator current. Changes in this parameter have the greatest impact on the current amplitude. On this basis, a quality indicator has been proposed using the difference in amplitudes of the measured and estimated stator current vectors:

$$
e_{i}=\frac{1}{k_{2}-k_{1}} \sum_{j=k_{1}}^{k_{2}}\left|\mathrm{i}_{s}^{m}(j)-\mathrm{i}_{s}^{e}(j)\right|,
$$

where: $k_{1}=t_{1} / T_{s}, k_{2}=t_{2} / T_{s}+1, T_{s}-$ sample time.

Table 1 shows the impact of IM parameters on this estimation quality indicator. The percentage value of the tested parameter is referred to as its rated value adopted in the IM model. For correctly identified parameters this index was equal to 0.0002 .

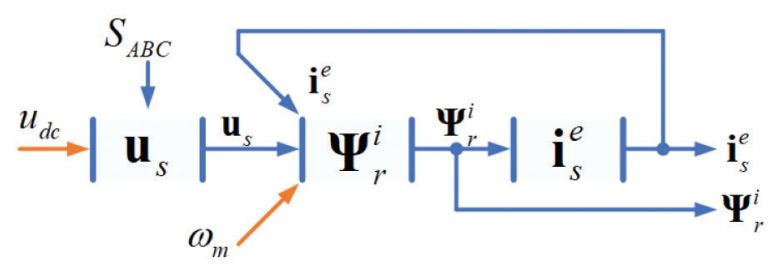

Fig. 2. Flow chart of the VCS algorithm

(a)

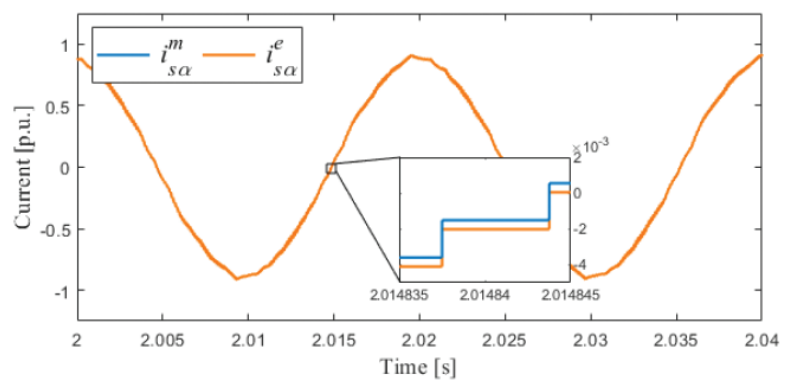

(c)

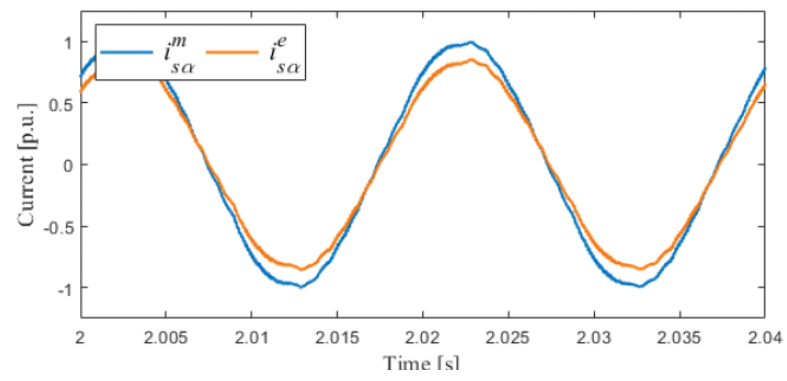

(b)

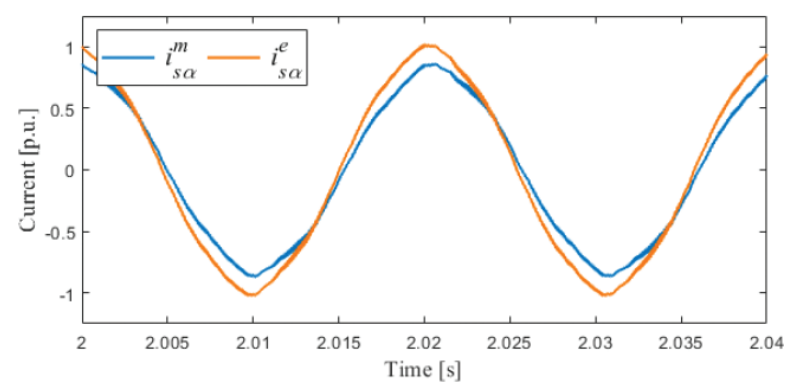

Fig. 3. The measured and estimated current $i_{\mathrm{sa}}$ for $r_{r}=r_{r}^{M}(\mathrm{a}), r_{r}=0.75 r_{r}^{M}(\mathrm{~b}), r_{r}=1.25 r_{r}^{M}$ (c) 
Table 1. Value of the current estimation quality indicator $e_{i}$ depending on IM parameters

\begin{tabular}{lccccc}
\hline$x / x^{N}$ & $r_{r}$ & $r_{s}$ & $I_{m}$ & $l_{\sigma r}$ & $l_{\sigma s}$ \\
\hline \hline $75 \%$ & 0.1533 & 0.0102 & 0.1015 & 0.0069 & 0.0030 \\
$125 \%$ & 0.1469 & 0.0104 & 0.0350 & 0.0074 & 0.0036 \\
\hline
\end{tabular}

(a)

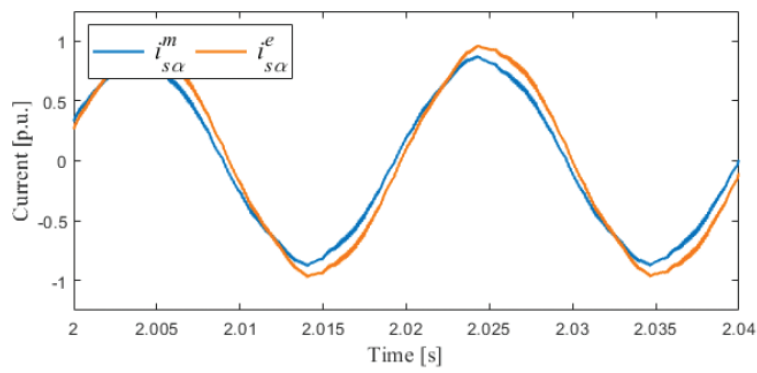

(b)

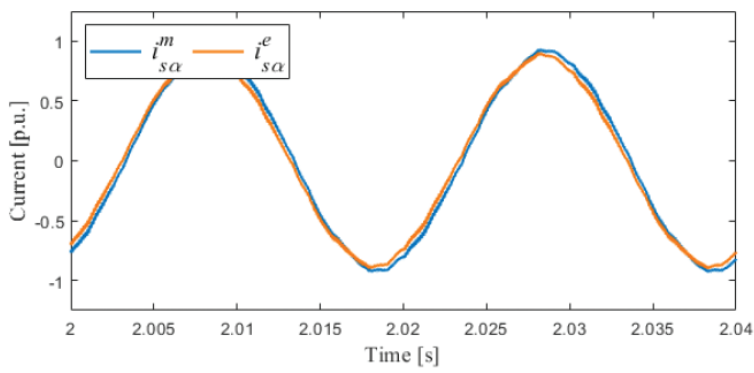

Fig. 4. The measured and estimated current $i_{\mathrm{sa}}$ for $I_{\mathrm{m}}=0.75 \mathrm{I}_{\mathrm{m}}^{\mathrm{m}}(\mathrm{a}), I_{\mathrm{m}}=1.25 \mathrm{I}_{\mathrm{m}}^{\mathrm{m}}$ (b)

The table above shows that not only the rotor resistance $r_{r}$ (Figure 3 ) but also the main inductance $I_{m}$ (Figure 4) has some impact on the quality indicator.

\subsection{Rotor resistance estimator}

The estimator of rotor resistance proposed in this article has a structure of an MRAS system. The adaptive part is the model of the virtual current sensor described in the previous subsection, while the reference part is the value of the measured phase current. The idea of this estimator is shown in Figure 5.

The output signal of the PI regulator in the above algorithm is the rotor resistance value (18), which is used for tuning the adaptive model (VCS) of the estimator:

$$
r_{r}^{e}=k_{P r}\left(\mathrm{i}_{s}^{m^{*}}-\mathrm{i}_{s}^{e^{*}}\right)+k_{I r} \int\left(\mathrm{i}_{s}^{m^{*}}-\mathrm{i}_{s}^{e^{*}}\right) d t,
$$

where: $k_{P r}, k_{l r}$ - the gains of the proportional and integral part of the PI regulator.

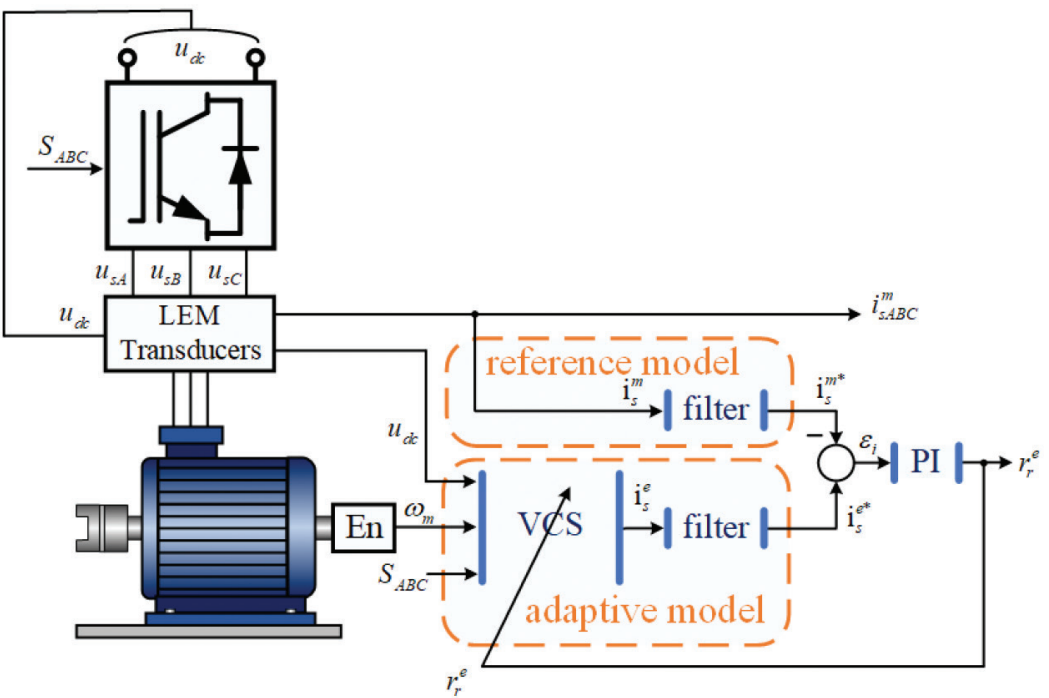

Fig. 5. Scheme of the proposed rotor resistance estimator algorithm 
To investigate the changes in amplitudes of the measured and the estimated stator current, which are the signals used in the rotor resistance estimator (Figure 5) in the drive system simulation model, the slow variations of the rotor resistance $r_{r}^{I M}$, in the IM mathematical model has been assumed as shown in Figure 6. Besides, the identification error of the rotor resistance equal to $110 \%$ of its nominal value was assumed in the DRFOC control structure. Then the drive system was tested in the operating system as shown in Figure 7 (a - reference speed, b - load torque). The simulation results are shown in Figure 8.

Because of the small calculation step in simulation tests and the modulation effect of the VSI transistors the current signals (Figure 8a) are characterised by a certain degree of change in their values. Therefore, they were filtered with a first-order filter, with a time constant of $0.1 \mathrm{~s}$. As can be seen, the higher the value of the rotor resistance in the motor model, the lower will be the value of the measured current and the higher will be the value of the estimated current.

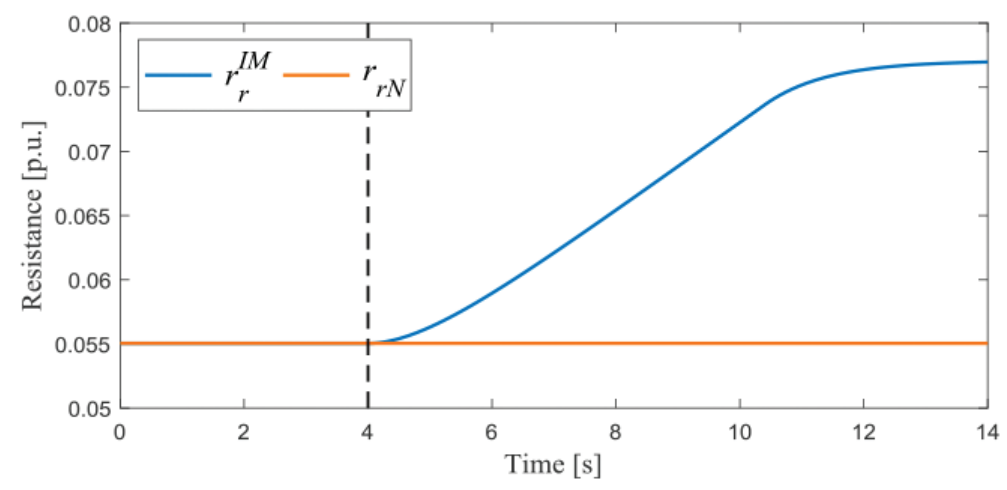

Fig. 6. Changes of rotor resistance in the IM model

(a)

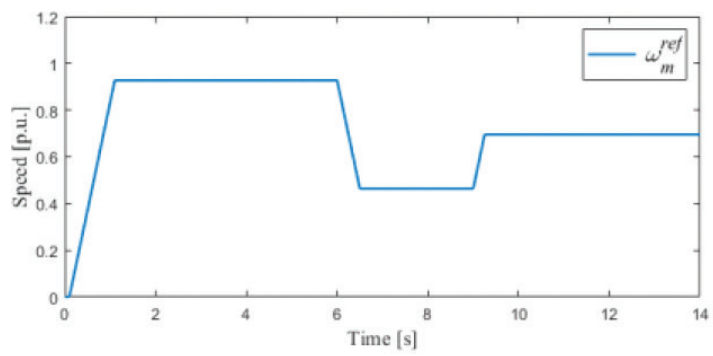

(b)

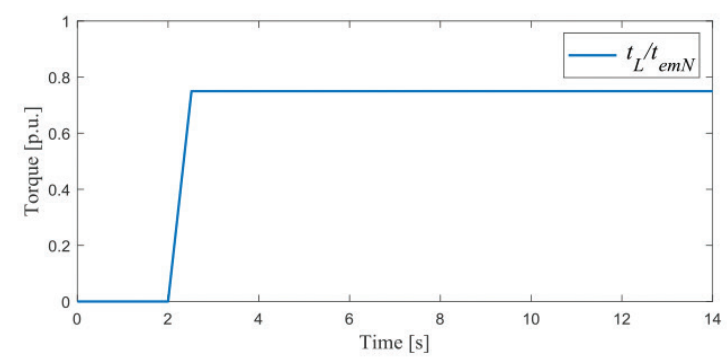

Fig. 7. Operating conditions of the drive system: reference speed (a), load torque (b) changes

(a)

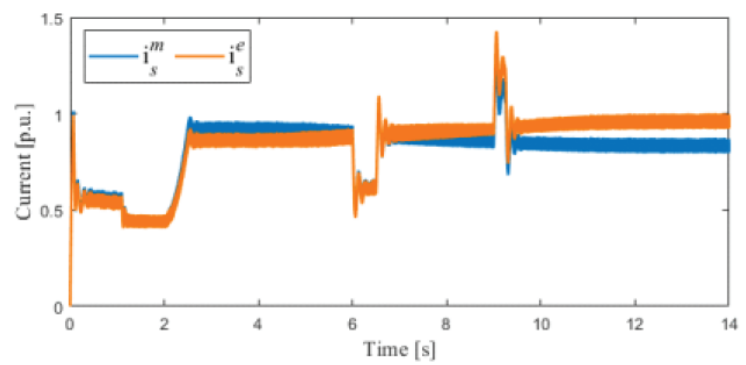

(b)

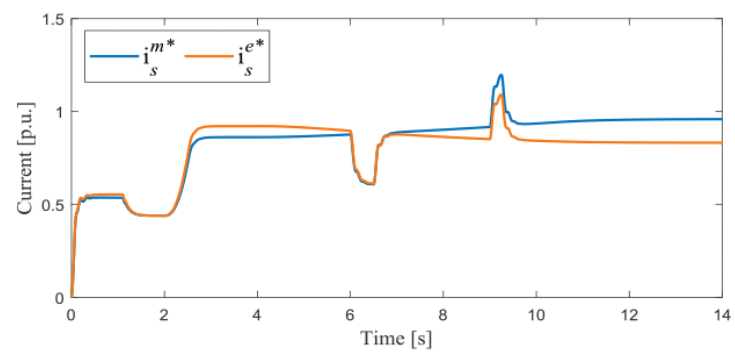

Fig. 8. Modules of measured and estimated stator current, before filtration (a), after filtration (b) 


\section{Rotor resistance estimator work analysis}

As shown in Table 1, the quality of phase current estimation, apart from the rotor resistance $r_{r}$, is also affected by the main inductance $I_{m}$. Besides, temperature changes in windings can affect not only the rotor resistance but also the stator resistance. Because of this, the impact of $r_{s}$ was checked too. Therefore, the tests of the proposed rotor resistance estimator were divided into two stages:

1 - analysis at a constant value of main inductance, where a mathematical model of IM with commonly used simplifications is assumed,

2 - analysis at a variable value of main inductance, where the variability of $I_{m}$ according to equation (10) is assumed.

The tests have been conducted without and with changes of stator resistance and were carried out for the rotor speed and load torque changing as shown in Figure 7. In both cases, the rotor resistance estimator started working in the 3rd second. The changing of stator resistance started in the 5th second from nominal to $140 \%$ of nominal value, as shown in Figure 9.

All tests were carried out in the DRFOC structure shown in Figure 10. It should be mentioned here, that ideal switches have been taken in the simulation model of VSI.

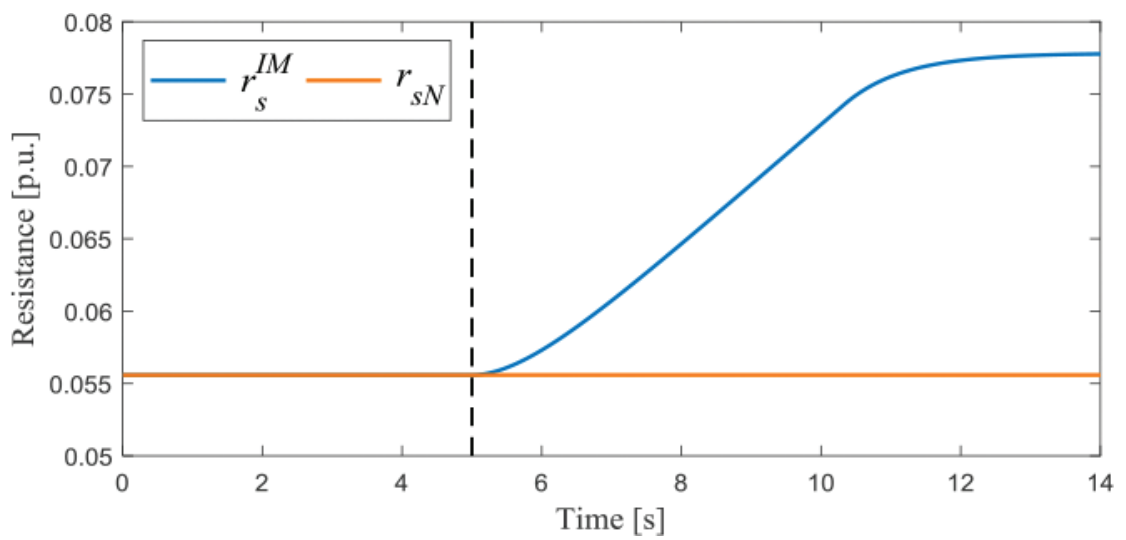

Fig. 9. Changes in the stator resistance during simulation tests

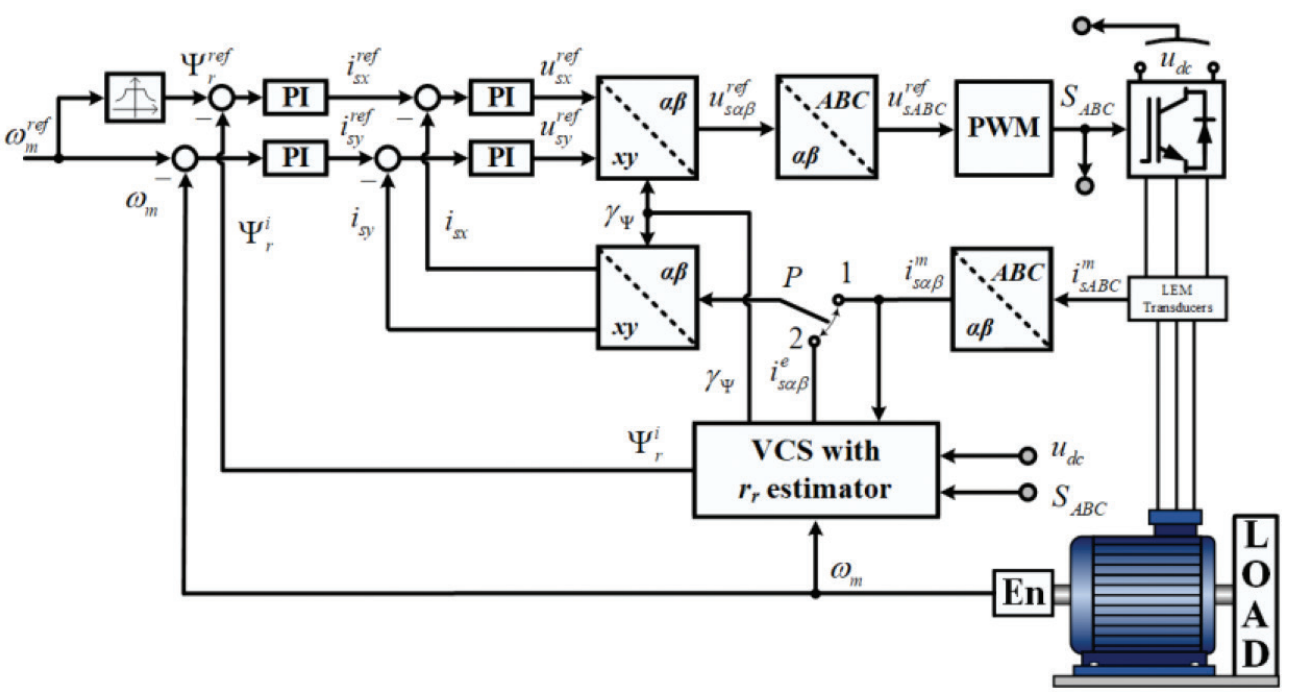

Fig. 10. DRFOC structure with virtual current sensor and rotor resistance estimator: switch $P$ in position 1 - classical control structure; switch $P$ in position 2 - fault-tolerant control (FTC) structure 
Michał Adamczyk

4.1. Analysis in the case of a constant value of the main inductance

Under the assumed operating conditions, the quality of rotor resistance estimation in the DRFOC system with a constant value of the main inductance was checked. The obtained results are shown in Figures 11-14 (a - test without, and $\mathrm{b}$ - with changing stator resistance).

It can be seen in Figure 11a that after switching on the estimator in the third second, the rotor resistance correctly follows the value adopted in the motor model for the constant value of stator resistance. Besides, this change is correctly tracked as it grows. For the test with changeable stator resistance (Figure 11b) the estimation error of the rotor resistance increases, however it is lower than 5\% (see Figure 14b). It can be noticed in Figure 12 that the signals entering the estimator overlap, which is connected with the improvement of the stator current estimation quality due to rotor resistance estimation (Figure 13). When the rotor resistance estimator is switched on, both the errors of estimating the stator current are going to zero value independently of the stator resistance value. As it was said above, the rotor resistance estimation error goes to zero value for constant stator resistance (Figure 14a) and reaches close to $5 \%$ for the stator resistance changed up to $140 \%$ of its nominal value, as shown in Figure $14 \mathrm{~b}$.

(a)

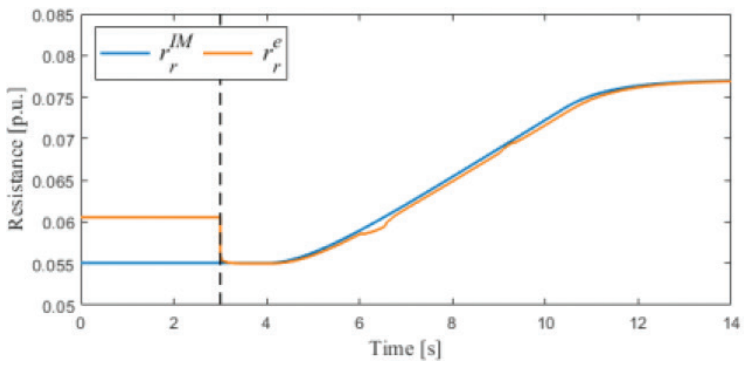

(b)

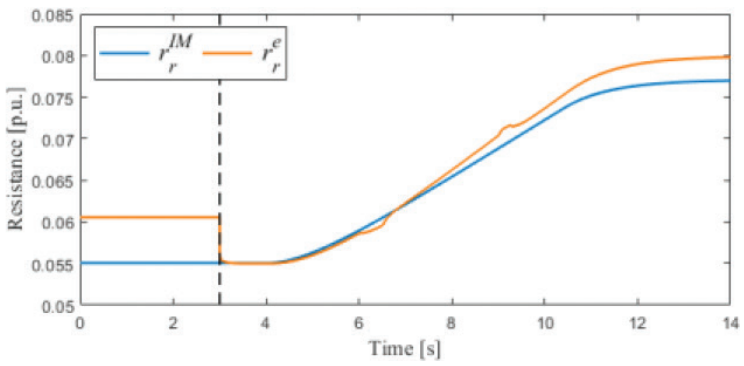

Fig. 11. Rotor resistance in $I M$ model and estimated one for $I_{m}=$ canst: test without changing $r_{s}$ (a), with changing $r_{s}$ (b)

(a)

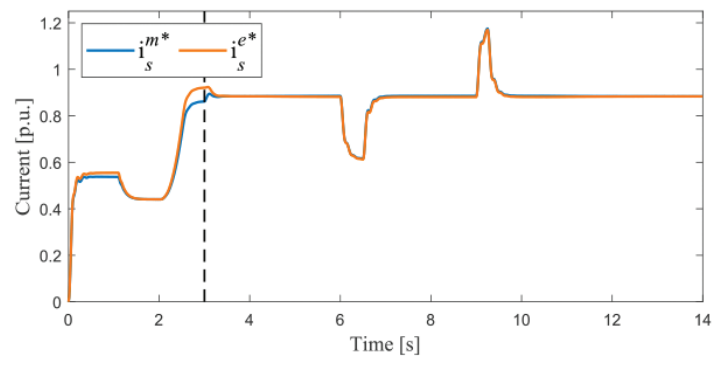

(b)

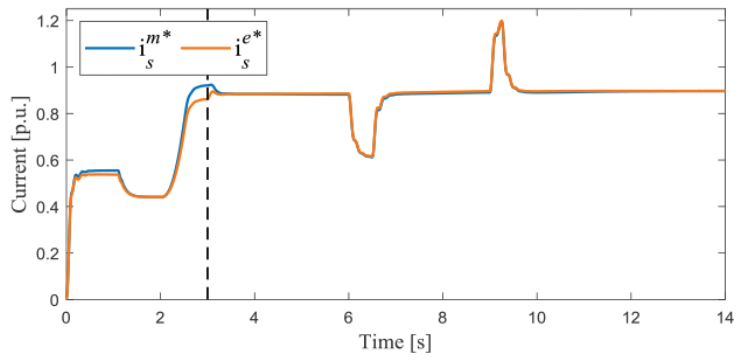

Fig. 12. Signals used in estimator for $I_{m}=$ cont: test without changing $r_{s}(a)$, with changing $r_{s}$ (b)

(a)

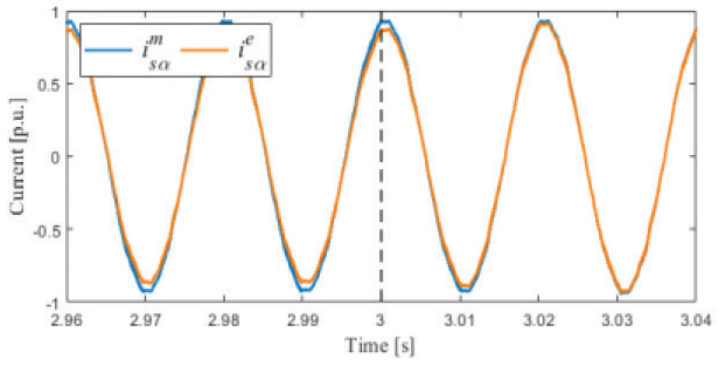

(b)

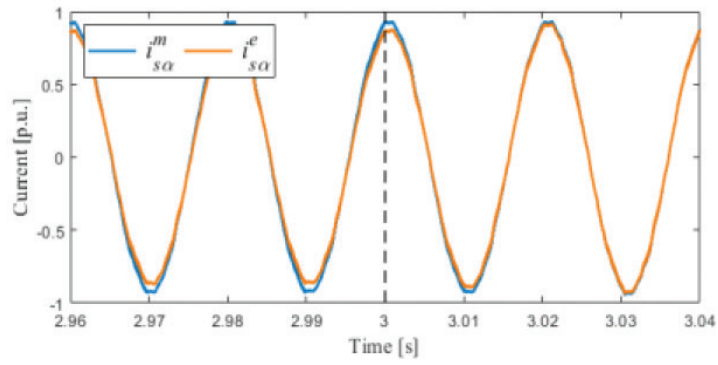

Fig. 13. Zoomed measured and estimated stator current $i_{s a}$ for $I_{m}=$ canst: test without changing $r_{s}(a)$, with changing $r_{s}(b)$

151 
(a)

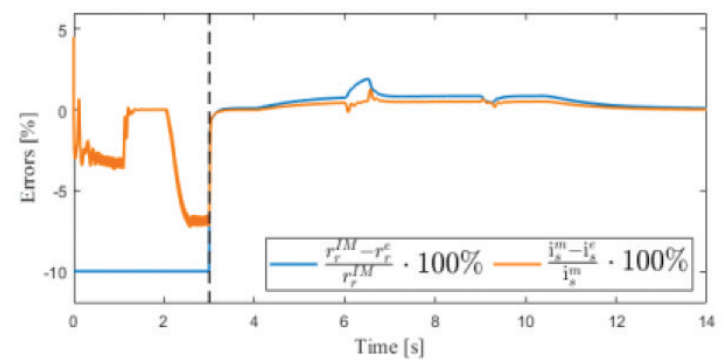

(b)

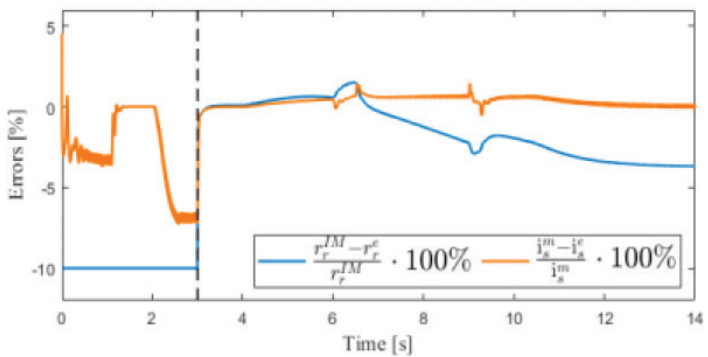

Fig. 14. Estimation errors of rotor resistance and stator current for $I_{m}=$ const: test without changing $r_{s}(a)$, with changing $r_{s}$

\subsection{Analysis in the case of a variable value of the main inductance}

The next stage of the research was to check the quality of rotor resistance estimation assuming a variable value of the main inductance, under the same operating conditions as before. The magnetising curve modelled according to (10) is shown in Figure 15, while the changes of $I_{m}$ during operation of the drive system, compared to its nominal value, can be seen in Figure 16. Also in this case the tests were carried out for constant and changeable stator resistance value. The results of the obtained tests are presented in Figures 17-20.

The above-mentioned transients show that also in the case of the IM mathematical model with magnetisation curve taken into account, the rotor resistance is estimated accurately according to the proposed algorithm for the

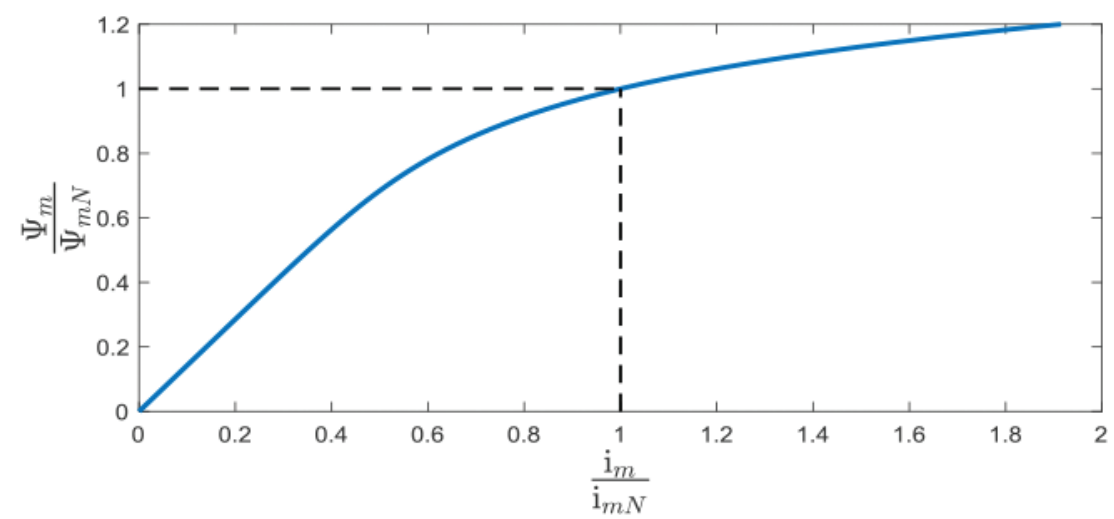

Fig. 15. Magnetisation curve

(a)

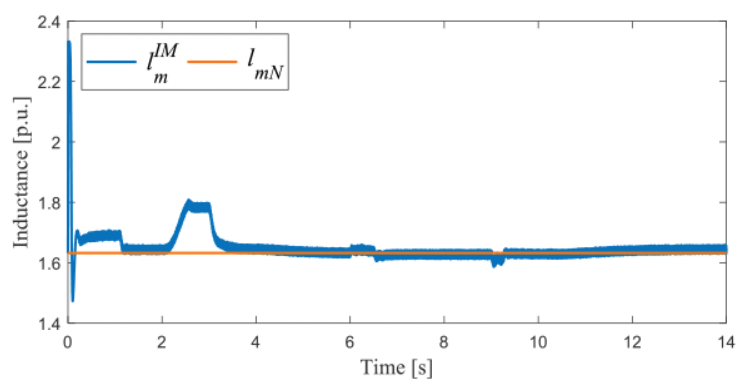

(b)

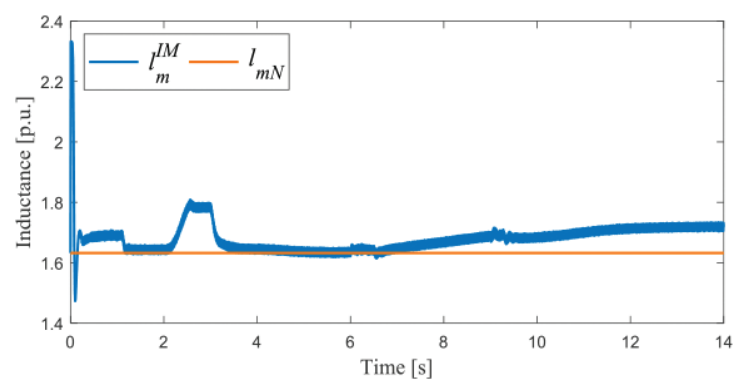

Fig. 16. Main inductance: test without changing $r_{s}(a)$, with changing $r_{s}(b)$ 
test without changing $r_{s}$ (Figure 17a). When the stator resistance is changing, the rotor resistance estimation error is a bit bigger than $5 \%$ (Figure 20b). The current signals used in the rotor resistance estimator coincide (Figure 18), which also indicates an improvement of the stator current estimation quality (Figure 19). It should be also mentioned that the estimation errors of the stator current are close to zero for constant and changeable stator resistance, however, the rotor resistance estimation error reaches around $5 \%$ in the case of stator resistance increased to $140 \%$, as can be seen in Figure $20 \mathrm{~b}$.

As it results from the simulation tests carried out, the rotor resistance estimation is somewhat sensitive to changes in $r_{s}$. However, it seems that its simultaneous estimation does not make sense because these errors in the estimation the rotor resistance of a few percent do not affect the quality of the current estimation.

(a)

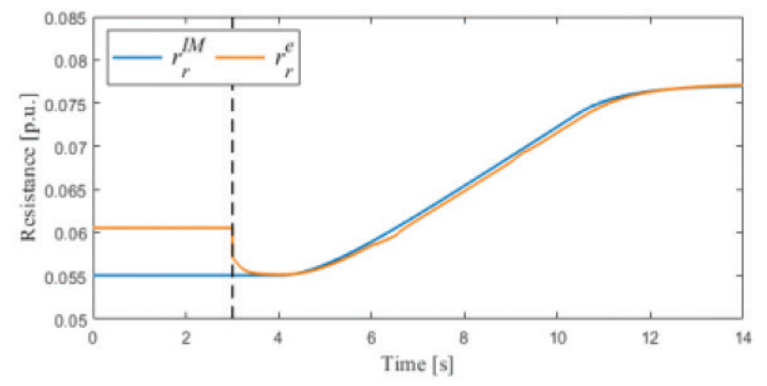

(b)

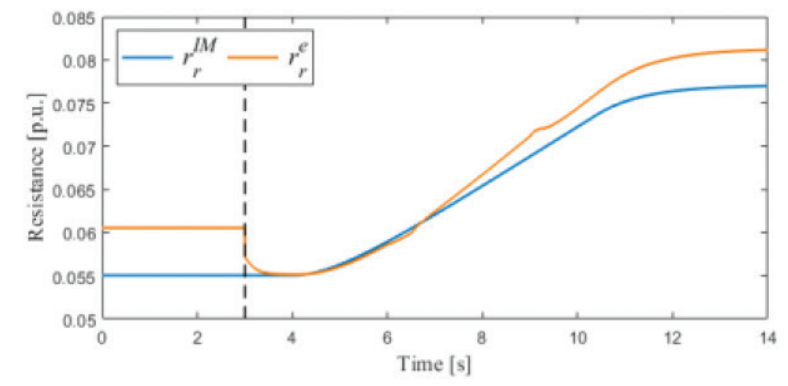

Fig. 17. Rotor resistance in $I M$ model and estimated one for $I_{m}=$ var: test without changing $r_{s}(a)$, with changing $r_{s}$ (b)

(a)

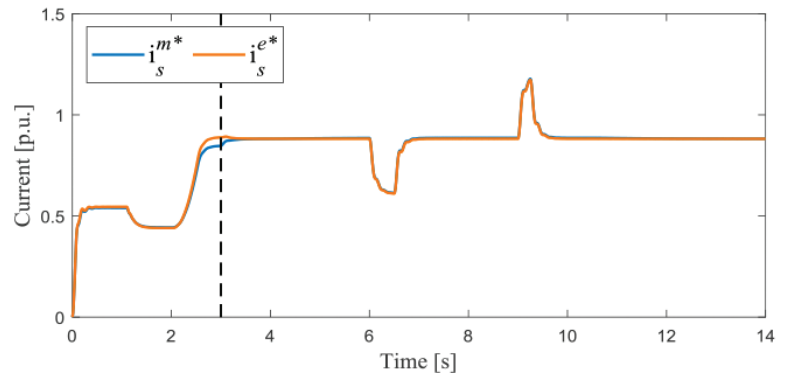

(b)

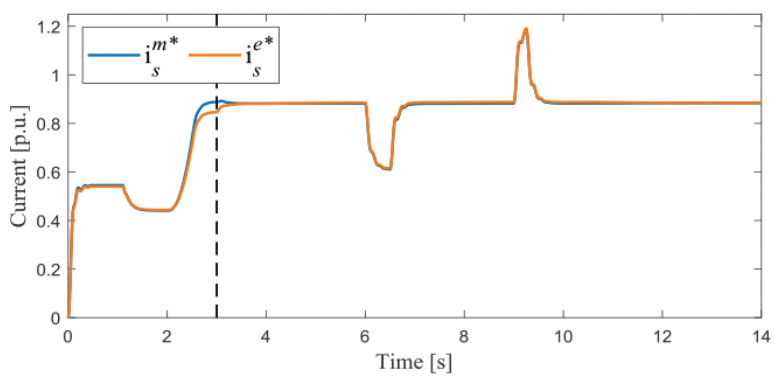

Fig. 18. Signals used in estimator for $I_{m}=$ var: test without changing $r_{s}(a)$, with changing $r_{s}(b)$

(a)

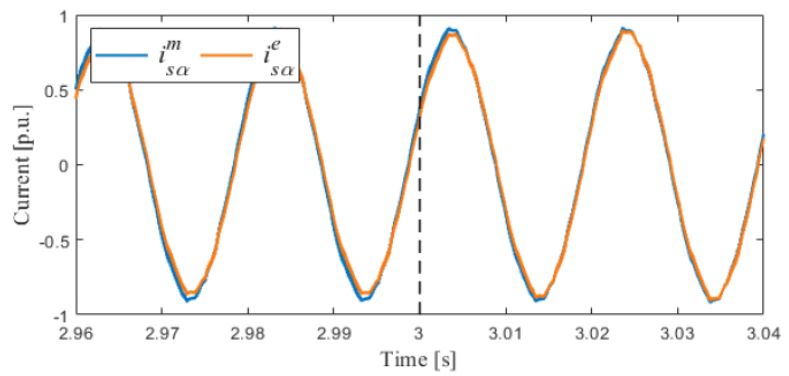

(b)

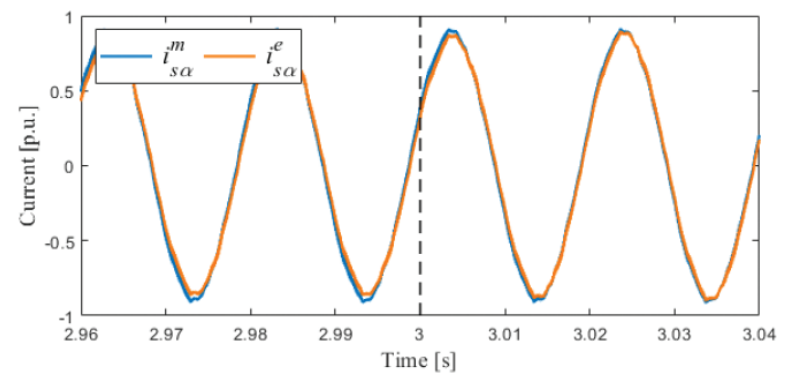

Fig. 19. Zoomed measured and estimated stator current $i_{s a}$ for $I_{m}=$ var: test without changing $r_{s}(a)$, with changing $r_{s}(b)$ 
(a)

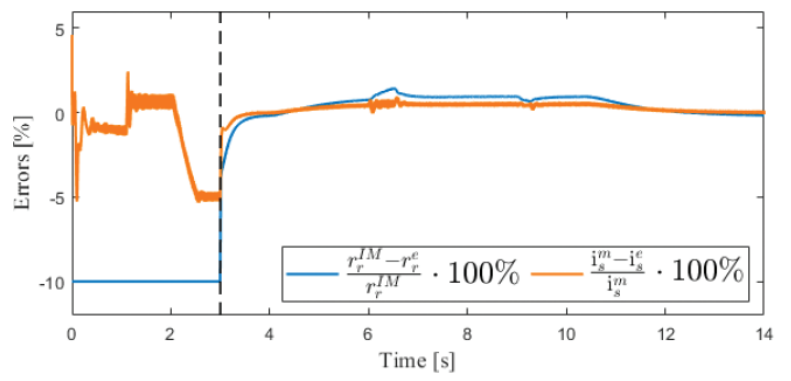

(b)

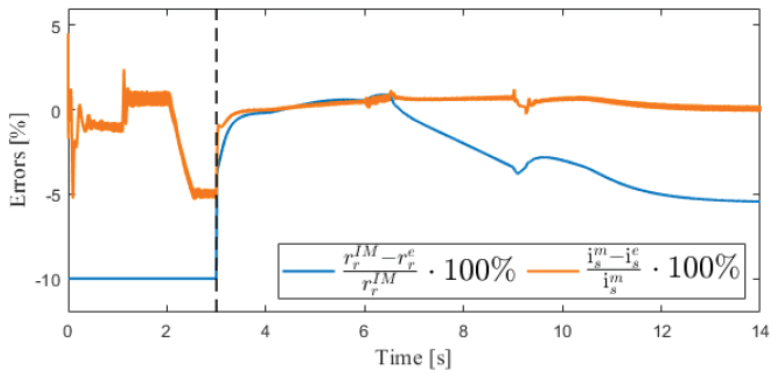

Fig. 20. Estimation errors of rotor resistance and stator current for $I_{m}=$ var: test without changing $r_{s}(a)$, with changing $r_{s}(b)$

\section{Conclusions}

The studies have shown that the developed rotor resistance estimator also works properly in a drive system model with a non-linear relationship between the flux and the magnetising current of the IM. Given the situation when the stator resistance is also changing ( $40 \%$ more than its nominal value), the estimation error of the stator current was close to zero while the rotor resistance error was around $5 \%$. This is not a significant obstacle, as the accuracy of the identification of the IM parameters is evaluated at around $10 \%$. Furthermore, the estimator of the rotor resistance helps to significantly improve the quality of the VCS regardless of the $r_{s}$ changes, and it can be used in the VCS algorithm to improve its performance. For example, in the failure-free operation of the IM drive, the estimated rotor resistance $r_{r}$ can be used in the current model of rotor flux. As the rotor resistance is a parameter with a low dynamics of change after the failure of the phase current sensors (when the proposed estimator cannot work) the average value $r_{r}$ from the last second before the drive reconfiguration can be adopted to the VCS algorithm. This solution will ensure a better quality of CS-FTC operation (switch $P$ from Fig. 10 in position 2). This issue will be the subject of further research.

\section{References}

Adamczyk, M. and Orlowska-Kowalska, T. (2019), Virtual Current Sensor in the Fault-Tolerant FieldOriented Control Structure of an Induction Motor Drive. Sensors, 19(22), p. 4979.

Barut, M., Demir, R., Zerdali, E. and Inan, R. (2012). Real-Time Implementation of $\mathrm{Bi}$ Input Extended Kalman Filter Based Estimator for Speed Sensorless Induction Motor. IEEE Transactions on Industrial Electronics, 59(11), pp. 4197-4206.

Du, T. and Brdys, M. A. (1993), Implementation of extended Luenberger observers for joint state and parameter estimation of PWM induction motor drive, In: 1993 Fifth European Conference on Power Electronics and Applications, Brighton, UK, 13-16 September 1993.

Dybkowski, M. (2018), Universal Speed and Flux Estimator for Induction Motor. Power Electronics and Drives, 3(38), pp. 157-169.

Dybkowski, M. and Orlowska-Kowalska, T. (2013), Speed Sensorless Induction Motor Drive System

with MRAS type Speed and Flux Estimator and Additional Parameter Identification, In: 11th IFAC International Workshop on Adaptation and Learning in Control and Signal Processing, Caen, France, 3-5 July, pp. 33-38.

Horváth, K. and Kuslits, M. (2018), Dynamic Performance of Estimator-based Speed Sensorless Control of Induction Machines Using Extended and Unscented Kalman Filters. Power Electronics and Drives, 3(38), pp. 129-144.

Kazmierkowski, M. P., Krishnan, R. and Blaabjerg, F. (2002), Control in Power Electronics-Selected Problems. Academic Press: Cambridge, MA, USA.

Levi, E., Sokola, M. and Vukosavic, S. N. (2000), A Method for Magnetizing Curve Identification in Rotor Flux Oriented Induction Machines. IEEE Transactions on Energy Conversion, 15(2), pp. 157-162.

Loron, L. and Laliberte, G. (1993), Application of the extended Kalman filter to parameters estimation 
of induction motors, In: 1993 Fifth European Conference on Power Electronics and Applications, Brighton, UK, 13-16 September 1993.

Mapelli, F. L., Bezzolato, A. and Tarsitano, D. (2012) A rotor resistance MRAS estimator for induction motor traction drive for electrical vehicles, In: 2012 XXth International Conference on Electrical Machines, Marseille, 2-5 September 2012, pp. 823-829.

Orlowska-Kowalska, T. (1989), Application of Extended Luenberger Observer for Flux and Rotor TimeConstant Estimation in Induction Motor Drives. IEE Proceedings $D$ - Control Theory and Applications, 136(6), pp. 324-330.

Orlowska-Kowalska, T. (2003), Sensoless Induction Motor Drives. Wroclaw University of Technology Press: Wroclaw, Poland.

Orlowska-Kowalska, T. and Dybkowski, M. (2016), Industrial Drive Systems. Current State and Development Trends. Power Electronics and Drives, 1(1), pp. 5-25.

Toliyat, H. A., Levi, E. and Raina, M. (2003), A review of RFO induction motor parameter estimation techniques. IEEE Transactions on Energy Conversion, 18(2), pp. 271-283.

Zai, LC., DeMarco, C. L. and Lipo, T. A. (1992), An Extended Kalman Filter Approach to Rotor Time Constant Measurement in PWM Induction Motor Drives. IEEE Transactions on Industry Applications, 28(1), pp. 96-104.

Zerdali, E. and Barut, M. (2018), Extended Kalman Filter Based Speed-Sensorless Load Torque and Inertia Estimations with Observability Analysis for Induction Motors. Power Electronics and Drives, 3(1), pp. 115-127.

Zorgani, Y. A., Jouili, M., Koubaa, Y. and Boussak, M. (2019), A Very-Low Speed Sensorless Control Induction Motor Drive with Online Rotor Resistance Tuning by Using MRAS Scheme, Power Electronics and Drives. 4(1), pp. 125-140.

Zorgani, Y. A., Koubaa, Y. and Boussak, M. (2010), Simultaneous estimation of speed and rotor resistance in sensorless ISFOC induction motor drive based on MRAS scheme, In: The XIX International Conference on Electrical Machines ICEM 2010, Rome, Italy, 6-8 September 2010. 


\section{Appendix A}

Table A1. Rated parameters of IM tested in simulation

\begin{tabular}{lcc}
\hline Parameter & [ph.u.] & [p.u.] \\
\hline \hline Rated phase voltage $U_{N}$ & $230 \mathrm{~V}$ & 0.707 \\
Rated phase current $I_{N}$ & $2.5 \mathrm{~A}$ & 0.707 \\
Rated power $P_{N}$ & $1.1 \mathrm{~kW}$ & 0.638 \\
Rated speed $n_{N}$ & $1390 \mathrm{rpm}$ & 0.927 \\
Rated frequency $f_{s N}$ & $50 \mathrm{~Hz}$ & 1.0 \\
Number of pole pairs $p_{b}$ & 2 & - \\
Rotor winding resistance $R_{r}$ & $5.064 \Omega$ & 0.550 \\
Stator winding resistance $R_{s}$ & $5.114 \Omega$ & 0.556 \\
Rotor leakage inductance $L_{\sigma r}$ & $31.6 \mathrm{mH}$ & 0.1079 \\
Stator leakage inductance $L_{\sigma s}$ & $31.6 \mathrm{mH}$ & 0.1079 \\
Main inductance $L_{m}$ & $478 \mathrm{mH}$ & 1.6323 \\
Mechanical time constant $T_{M}$ & $0.25 \mathrm{~s}$ & - \\
Rated rotor flux $\Psi_{r N}$ & $0.7441 \mathrm{~Wb}$ & 0.7187 \\
Rated stator flux $\Psi_{S N}$ & $0.8235 \mathrm{~Wb}$ & 0.7954 \\
Rated magnetic flux $\Psi_{m N}$ & $0.7518 \mathrm{~Wb}$ & 0.7261 \\
\hline
\end{tabular}

